\title{
Snakes and ladders: The development and multiple reconstructions of the Stockholm International Peace Research Institute's military expenditure data
}

\section{Sam Perlo-Freeman and Elisabeth Sköns}

Sam Perlo-Freeman is Head of the Military Expenditure Project at the Stockholm International Peace Research Institute (SIPRI), Stockholm, Sweden. He may be reached at perlo-freeman@sipri.org. He will shortly take up a position at the World Peace Foundation at Tufts University, Boston, MA, USA, as Project Manager for Global Arms and Corruption. Elisabeth Sköns is a Senior Associate Fellow at the Stockholm International Peace Research Institute, Stockholm, Sweden. She may be reached at eskons@sipri.org.

\section{Abstract}

The Stockholm International Peace Research Institute's military expenditure database is the only long-run, consistent dataset on military expenditure with global coverage. Even though SIPRI's military expenditure data collection dates back almost to the organization's beginning in 1966, until recently, consistent data series for most countries have only been available as from 1988 onward. As this article discusses, the history of SIPRI's military expenditure project includes a number of breaks, the result of staff transitions and failures of record-keeping. As a result, reconstructing the data has been necessary on a number of occasions. The most recent such effort has now succeeded in extending the data backward from 1988 for the great majority of countries - in most cases at least to the 1960s, and for some countries as far back as 1959. This article sets out this history of advances, setbacks, and reconstructions and the methodologies used. In particular, the results of the latest reconstruction effort are presented, and thoughts for future developments laid out.

$\mathrm{M}$ litary expenditure data has been a core topic for the Stockholm International Peace Research Institute (SIPRI) ever since its establishment in 1966. The rationale behind the Institute's founding was the provision of impartial data and information on armaments to be used as a solid basis for disarmament proposals and negotiations. The initial idea for SIPRI's creation came from the Swedish ambassador to the nuclear disarmament negotiations in Geneva in the 1960s - Alva Myrdal — and was focused on the provision of data on nuclear weapons. However, by the time SIPRI was established, the mission of impartial data provision also encompassed biological and chemical weapons, international arms transfers, and military expenditures. Thus, during SIPRI's first years, an intensive process was set in motion to gather, conceptualize, process, and document data on various aspects of armaments.

Although the Institute's flagship publication, the SIPRI Yearbook, has included tables of military expenditure data in all but two volumes (1993 and 1994), until recently SIPRI's online military expenditure database only provided data as from 1988 onward. This is the result of various historical hiccups, mishaps, and personnel transitions that happened along the way. As a result, it has been necessary to recreate and reconstruct the data collection three times: In 1979, the data was reconstructed back to 1950. In 1997-1998, a 10-year series (for 1988-1997) was reconstructed. Finally, in 2015, a reconstruction of the data before 1988 was completed, fulfilling a long-standing goal of the military expenditure project and meeting widespread demand among researchers for long data series on military expenditure. This extended dataset, which in some cases goes back as far as 1949, and to at least 1957 for a majority of countries that were independent political entities at the time, is as available as a beta version on request from SIPRI. It is intended for a final version to be made freely available online in November 2016.

This article describes the history of SIPRI's military expenditure data collection efforts, the sources and methods used, problems encountered, and the three data reconstruction efforts that we have led over the years. The following sections describe the initial founding of the project, the first two reconstructions led by Elisabeth Sköns, and the most recent reconstruction led by Sam Perlo-Freeman. This includes a statistical presentation of the degree of success the project has enjoyed, along with priorities for future development.

\section{How the SIPRI military expenditure project started}

As mentioned, military expenditure data collection was one of the main objectives of the establishment of SIPRI itself in 1966 and part of the broader project of publishing an annual record, the SIPRI Yearbook. The first Yearbook (1968/1969) presented 
its aim as "to produce a factual and balanced account of a controversial subject - the arms race and attempts to stop it." It was designed to fill a gap: "Until now there has been no authoritative international source which provided-in one place-an account of recent trends in world military expenditure, the state of the technological arms race, and the success or failure of recent attempts at arms limitations or disarmament."

\section{Purpose of the data}

Initially, the purpose of the collection of "military expenditure material" was presented in rather modest language, "to answer questions about long- and short-term trends in military expenditure, in individual countries, regions and the world as a whole." Subsequently, the aim of the military expenditure data was presented in "opportunity cost" terms, i.e., to indicate opportunities forgone by allocating government expenditure for military purposes. Later, a budget priority rationale was added, i.e., that comparison of data on military and nonmilitary expenditure can be used also as an indicator of governments' political priorities between various purposes. $^{2}$

From the outset, there was a clear statement about the limitations of the data: "Because of differences in coverage and the difficulty of finding appropriate exchange rates, expenditure figures are often unsuitable for cross-country comparisons ... They do, however, provide a good basis for commenting on the rate at which military expenditure is rising." 3

\section{Methods}

The purpose of presenting the military expenditure data has had some impact on the definition and methods used for collecting and processing the data. The definition of military expenditure has consistently been based on the understanding of military expenditure data as an indicator of inputs - of financial resources - into the military sector rather than of outputs - such as military capability or strength. For example, military aid is included in the data for the donor country and excluded from that of the recipient country. In practice, the lack of detailed data makes implementing such principles challenging, and thus the definition has served primarily as a guideline for the collection and processing of the data.

From the very beginning, military expenditure data were shown not only in local currency at current prices, but also in U.S. dollars at constant prices and exchange rates - and a few years later, also as a share of national product. Due to fundamental differences between market and centrally planned economies, comparison of military expenditure across countries and over time was a specific challenge during the
Written by the two most recent primary participants in the effort, this article reviews the history of the Stockholm International Peace Research Institute's military expenditure dataset.

cold war period. This meant that there was no standardized system of exchange rates and price indices. For Warsaw Pact countries, Western economists developed approximate currency conversion rates and price indices, some of which were used by SIPRI.

While there were problems to apply a standardized definition of military expenditure to all countries, and while cross-country comparisons of military expenditure continue to involve numerous conceptual issues, one thing that could be applied was consistency over time. This was from the beginning, and remains now, the main principle in the data collection and processing.

Sourcing of data must have been a considerable challenge during the first years. According to the earlier Yearbooks, the sources on military expenditure data included primarily the United Nations (United Nations Statistical Yearbook, UNSY), publications by NATO for NATO countries, the U.S. Agency for International Development (USAID) for developing countries, and the Statesman's Yearbook. In exceptional cases, data were consulted from other military expenditure data collections such as those of the International Institute for Strategic Studies (IISS) and the U.S. Arms Control and Disarmament Agency (ACDA) but, in general, these were avoided since these do not always use open sources.

\section{The first reconstruction of data series}

When Elisabeth Sköns arrived at SIPRI as a student in late 1978 to compile a set of tables on military expenditure, there was virtually nothing to inherit apart from the SIPRI Yearbook itself, and a small box of cards with information of the sources used for some countries. In addition, she received a set of instructions from Frank Blackaby who had directed the data collection processes and preparations for the first Yearbooks, a pile of empty paper worksheets, and a calculator. For each country, she started two work sheets, one for the military expenditure data from all the sources she could identify (with one column for the final SIPRI data series), and one worksheet for calculations, converting military expenditure figures into calendar years (when applicable), constant dollars, and shares of GDP.

During the 1980s, the number and quality of sources used for SIPRI's military expenditure data collection expanded significantly, partly because additional existing sources were 
identified and partly because new sources emerged. These included (1) the International Monetary Fund's Government Finance Statistics Yearbook(GFSY), which began publication in 1977, providing data on government expenditures, including a one-liner for "Defense," (2) IMF country reports, and (3) the World Bank's World Tables, which had long series of data for developing countries. The central statistics office in Stockholm also had a great variety of statistics on exchange from other countries, which often had military expenditure data, even for Middle Eastern countries. Some national statistical offices also produced statistics for other countries. Most important among those was Statistik des Auslandes, published by Germany's Statistisches Bundesamt (the National Statistics Office or Agency) in Wiesbaden, Germany. Another useful source was U.S. State Department reports to Congress, which presented justifications for U.S. development aid to individual recipients, along with background information including military expenditure data.

The use of these standardized sources largely precluded any recalculations of the data to adhere to the SIPRI definition of military expenditure. In exceptional cases, when alternative series were available, the guideline definition could serve as a basis for choice between series.

During the 1980s and early 1990s, great efforts were also made to identify and use primary sources, i.e., national budgets and government expenditure accounts. The limited staff resources in the military expenditure project constrained such efforts. However, when a major discrepancy between national data and the SIPRI guideline definition was identified, an effort was made to initiate special studies. One example of this was a commissioned study on Israel to identify and subtract military aid received from official military expenditure figures. A similar in-house effort was made for Egypt. ${ }^{4}$

One of the most detailed data collections on military expenditure of developing countries emerged in the early 1980s. This was the seminal data compendium by Nicole Ball, a U.S. American researcher, who set out to create a solid empirical base for her line of argument in the debate on the relation between defense and development in developing countries. Her collection also became a useful source for SIPRI. ${ }^{5}$

\section{The second reconstruction}

In 1997-1998, a second major effort to reconstruct SIPRI's military expenditure data was required. This was because the project had experienced a number of difficulties since 1987. First, due to the lack of reliable data for Russia and China and due to the concern that the lack of cross-country comparability of the data compromised the validity of regional totals, the practice of aggregating country data on military expenditure into regional and world totals was abandoned in $1987 .^{6}$

Second, due to a staffing transition, the military expenditure project did not produce any data at all in 1993 and 1994. More importantly, no background material (sources of data and calculations of figures) was left behind for the years 1985-1997. Thus there was a need for a comprehensive restart of SIPRI's military expenditure database. The reconstruction, carried out by Elisabeth Sköns, who returned to the project for this purpose, included the following steps.

First, SIPRI's guideline definition of military expenditure, based on the NATO definition, was revisited. As mentioned, because of both conceptual issues and data availability, the definition was difficult to apply in practice. One difficult issue concerned the inclusion of the cost of paramilitary forces "when they are judged to be trained and equipped for military operations." Assessment of this criterion requires specific knowledge on the respective paramilitary forces. The inclusion of retirement pensions also presents a problem, in particular for countries with a social security system that does not include pension fees in personnel costs.

Second, to identify and assess various sources of military expenditure for each of the 158 countries then covered in the tables a priority list of data sources was established. Priority one was accorded to primary sources, i.e., official national government data, including responses to SIPRI Questionnaires requesting data in standardized form, and government reports to the United Nations and the Organization for Security and Co-operation in Europe (OSCE). Priority two was secondary sources reproducing data provided by governments, such as the GFSY, the UNSY, NATO, and a few others. Finally, priority three sources consisted of specialist journals and newspapers. ${ }^{8}$

Third, the project started to build up a network of experts to assist SIPRI both in gathering official public expenditure data and in conducting targeted studies to recalculate official government expenditure data into military expenditure series more closely matching the SIPRI guideline definition. The most important examples were the studies to develop a method of calculation and a first 10-year series of military expenditure estimates for the former Soviet Union and Russia produced by Julian Cooper in 1998 and for China produced by Shaoguang Wang in 1999. These two series were necessary also to enable the production of a series for total world military expenditure. Much later, Prof. Nurhan Yentürk produced a detailed series of estimates for Turkey. ${ }^{9}$

Fourth, in regard to processing of the data, given the practical difficulties in producing military expenditure series according to a common definition, the overarching principle for producing the SIPRI series continued to be as far as 
possible to achieve consistency and comparability over time.

While cross-country comparisons were advised against, it was realized that such comparisons were made nevertheless. Thus, the issue of conversion rates had to be resolved. Since the official exchange rates did not accurately reflect the price ratios of their economies, for countries in transition from a centrally planned to a market economy (primarily the former Warsaw pact countries), GDP-based purchasing power parity (PPP) rates were used for the conversion from local currencies to U.S. dollars. ${ }^{10}$

Additionally an effort was made to look into the option of using GDP-based PPP's for all countries. A World Bank-commissioned project to produce PPP rates had made progress. In particular, the country coverage had been greatly expanded, although based on a short-cut method. According to the World Bank, the quality of the PPP rates had also been improved. ${ }^{11}$

A comparison of military expenditure by market exchange rates and PPP rates for selected countries was presented in the 1999 Yearbook. This showed that for developing countries and countries in transition the choice of conversion rate had a huge impact on the calculated level of military expenditure in U.S. dollars. At the same time, using GDP-based PPP rates for translating military expenditure data into a common currency involved significant uncertainties in interpretation and large margins of error. Nonetheless, and primarily for transparency and educational reasons, the 2003 Yearbook started to present data for the largest spenders at both market exchange rates and at PPP rates. ${ }^{12}$

Fifth, to facilitate the generation and analysis of the data, computerization of the data collection was initiated in 1998, and a database was created, albeit a very rough and rudimentary one.

\section{Extending the data back before 1988}

Ever since the 1997-1998 reconstruction of the military expenditure database back to 1988 , it has been an important aspiration of the project to extend the data back further, if possible to around 1950. The major problem was always resourcing, in particular staff time, to go through the vast archives of military expenditure source material collected by SIPRI over the years, and to analyze these sources to produce consistent long-term series.

After assuming responsibility for the military expenditure project in 2009, Sam Perlo-Freeman made backdating data a high priority. After two unsuccessful funding applications, the opportunity to start the process came in 2010 when a Ph.D. defense economics student (Jennifer Brauner), who wanted extended data for the Middle East for her work, came to SIPRI as an intern to work on gathering the data herself. After she had gone through and documented all available archival sources, she and Perlo-Freeman went through the resulting data and found that it was indeed possible to construct consistent series for most countries in the region going back to the 1970s, the 1960s, and even earlier. Following this pilot work, SIPRI sought other students and researchers interested in pursuing the backdating effort for other regions. ${ }^{13}$

This continued, intermittently, up to spring 2015, when Latin America was the last region covered. This was followed by gathering of additional economic data, data entry, error-checking, and the production of usable data sheets. The dataset was then sent in summer 2015 for "alpha testing" by a group of defense economists and other academic experts. The initial research results produced by this group were discussed, along with issues relating to the data itself, at a January 2016 workshop organized by SIPRI and funded by the Swedish Riksbankens Jubileumsfond. (The other articles in this symposium are based on the work presented at this workshop.) This process led to further improvements in some of the data series, prior to the release of the "beta" version of the dataset in April 2016. As mentioned SIPRI hopes to publicly launch a final version, which will be available online, in November $2016 .^{14}$

\section{Sources and methodological difficulties}

A wide variety of sources have been used in reconstructing the extended dataset. As mentioned, source use was ranked by priority. The most important sources, by category, are domestic sources, IMF data, UN data, NATO data, expert analyses, and other statistical sources.

Domestic sources of data, such as government budget and expenditure documents, responses to SIPRI questionnaires and other requests for information, and national statistical yearbooks, account for 28 percent of all data points before 1988. As primary, official data, these are the most preferred sort of data to use, where available. The IMF's Government Finance Statistics Yearbook (GFSY) and other IMF publications account for 21 percent of all data points before 1988. The GFSY (and the online GFS database covering the period from 1990 onward) presents expenditure data reported by governments back to 1970, using the IMF/World Bank Classification of the Functions of Government (COFOG), one of which is defense. The availability of this data is patchy - and particularly weak in recent years. Moreover, the COFOG definition of defense does not correspond to SIPRI's definition of military expenditure. In particular, the former excludes military pensions. Nonetheless, for earlier periods it is often one of the best data sources readily available. ${ }^{15}$ 
The United Nations Statistical Yearbook (UNSY), and the UN Statistical Yearbook for Asia and the Pacific, also account for 21 percent of all data points before 1988 as well. UNSY used to provide data on countries' military spending, along with a range of other data. Where both sources are available, UNSY most often agrees with GFSY. NATO data on the military expenditure of its member states account for 17 percent of the pre-1988 data, and 55 percent of the data for European countries. NATO uses a definition of military expenditure very close to SIPRI's. ${ }^{16}$

Expert budget analyses and estimates account for 6 percent of data points before 1988. Most of these (72 percent) are expert analyses of national budgets and expenditure and thus are closely based on primary, domestic sources, but often including items of expenditure outside the official defense budget. The remainder are estimates by U.S. analysts for some former Warsaw Pact nations. Statistik des Auslandes, a German publication that used to give statistical data on countries worldwide, provides 4 percent of data points before 1988. This source also often, but not always, agrees with GFSY where both are available. Finally, other sources, including the U.S. Arms Control and Disarmament Agency (ACDA), the Europa Yearbook, media sources, other secondary sources, and unidentified sources from previous SIPRI worksheets, account for 3 percent of the pre-1988 data points.

Over the past two decades, the proportion of countries producing military expenditure data has increased modestly, from 88 percent in 1994 to 94 percent in 2014, although this may be as much a matter of greater accessibility of data via the internet as of increased transparency. Moreover, while there still are major problems with transparency in many countries, the general quality of the data that is available has greatly increased in many cases. Detailed budget documents are frequently made available online, along with reporting of past expenditure. It is much more often possible to find information on spending on military pensions and on paramilitary forces. Ironically, the improved quality of data now available creates challenges for extending the data backward in time, namely how to connect the current series to older, often lower-quality data, in a consistent manner! $!^{17}$

It is, therefore, rarely possible to find a single data source that covers the entire period of available data for a single country. Even developed countries with strong, transparent reporting systems, have frequently changed their methods of reporting and accounting. It has almost always been necessary to combine data from more than one source, and sometimes several, to obtain long time series of data. To try to ensure consistency over time, a number of key principles, based closely on the sources and methods for military expenditure data developed during the 1997-98 reconstruction, were applied. ${ }^{18}$

First, wherever possible, we tried to use data series that overlapped in their time coverage, so that the extent to which they agree with each other on overlapping years can be assessed. Second, if overlapping series could not be found, we would look for evidence that separate series represented the same concept of military spending, for example the Ministry of Defense budget (an institutional definition) or a functional definition based on COFOG. Third, in a small number of cases - and where this did not give unexpected jumps or dips in real values - we have combined series even without clear evidence of interconsistency. Fourth, where different series did overlap in their time coverage, we would combine the series as they stood if the difference between them on the transition year was less than about 3 percent. In some cases, if we had several years of overlap and a variable relation between them (i.e., sometimes one series was higher, sometimes the other), we would also combine them directly. Where series overlapped, but one was consistently higher than the other (by more than 3 percent), we would apply a percentage change estimate, adjusting one of the series (usually the older) upward or downward by a fixed percentage to bring the two series into agreement on the transition year between them. This continues to be the practice used by SIPRI for combining military expenditure data series from at least the 1979 reconstruction. This factor is more significant, the older are the data. While 16 percent of data points from 1988 onward are estimates of one sort or another, or are marked as "highly uncertain," 37 percent of the data before 1988 are classified in this way (and 26 percent of the entire dataset). ${ }^{19}$

In a number of cases the use of percentage change estimates may give rather uncertain results, as this method relies on the assumption that the later series-were are available - would have followed the same trend as the older series. Alternatively, supposing that the later series includes a component such as pensions that is absent from the earlier series, the method assumes that this component follows the same trend as the rest of military spending. This may not be correct, and the greater the proportionate adjustment made to the older series, and the more years for which the percentage change estimate is made, the greater the likely margin of error. There are 9 countries where, at some point, a greater than 50 percent adjustment has been made to the raw data to produce the estimate, including one where the raw data has been more than doubled. In a further 14 cases, an adjustment of between $30-50$ percent has at some point been made to the raw data. ${ }^{20}$

Nonetheless, series based on percentage change estimates are at least correctly measuring the trend in some definition of 
military expenditure (assuming that the source data accurately reflects the definition of military spending it purports to measure). The series as a whole, therefore, can be taken as a reasonable index of trends over time, while also reflecting the approximate absolute level of military spending based on the best available data.

Importantly, that a series for a country does not involve estimates does not necessarily mean that the data is of a higher quality. If all the available sources for a country agree exactly with each other, for example, it probably means that they all originate from the same official source, which may itself be unreliable for the usual reasons-omission of elements of military spending from the definition (e.g., pensions), extra-budgetary and off-budget sources of military spending, poor monitoring and reporting of actual expenditure, and so on. This, however, is an unavoidable feature of working with military expenditure data. Ultimately, the reliability of SIPRI data is always dependant on the reliability of official sources (or occasionally estimates based on these sources), as SIPRI does not make use of intelligence-based or other non-open sources.

\section{Results of the backdating exercise}

The backdating effort was carried out without external funding, relying on volunteer interns, guest researchers, and unfunded SIPRI staff time. Thus, its scale and ambition was necessarily limited, relying on sources already available in SIPRI's archives, including media clippings, correspondence with data providers, questionnaire responses, official documents obtained from various sources, and reference works such as the IMF's GFSY and the UN's UNSY. In particular, this meant that backdating attempts could not be made for the USSR and China, as to produce meaningful estimates for these two key countries would require dedicated expert studies.

Nonetheless, we were able to extend the series at least to some degree for the great majority of countries. However, the extent of the backdating is highly variable. Table 1 shows, for various points in time, the total number of countries in the SIPRI database that were independent at the time, and the proportion of these countries for which we now have, respectively, local currency and constant USD2014 military expenditure data. (The first year of the published SIPRI database, 1988, is given as a reference point.) There is thus a steady fall-off of data availability, with the decline particularly steep over the 1950s. The first year for which half of countries have constant price data is $1957 .^{21}$

The regions of best data availability are consistently Europe and the Americas. The (combined) region of Asia and Oceania has the highest proportion of countries where little or no
Table 1: Data availability by year

\begin{tabular}{|c|c|c|c|}
\hline \multirow[b]{2}{*}{ Year } & & \multicolumn{2}{|c|}{ Proportion (in percent) } \\
\hline & $\begin{array}{c}\text { No. of } \\
\text { countries }\end{array}$ & $\begin{array}{l}\text { Local currency, } \\
\text { current prices }\end{array}$ & $\begin{array}{c}\text { US dollar, } \\
\text { constant prices }\end{array}$ \\
\hline 1988 & 144 & 88 & 82 \\
\hline 1980 & 142 & 83 & 77 \\
\hline 1975 & 140 & 76 & 69 \\
\hline 1970 & 131 & 74 & 66 \\
\hline 1965 & 124 & 68 & 57 \\
\hline 1960 & 109 & 63 & 51 \\
\hline 1955 & 85 & 45 & 36 \\
\hline 1950 & 83 & 34 & 22 \\
\hline
\end{tabular}

backdating was possible. For African and Middle Eastern countries a small portion could be taken back before the mid-1960s.

As mentioned, the reliability of the data is constrained by the quality of the sources we have to work with. Problems such as off-budget spending on arms imports, or of military expenditure hidden in other budget lines, are in most cases not solvable, especially when the only available sources are secondary ones such as GFSY and UNSY. In recent times, primary source data is much more readily available compared to the backdated data. Even so, these problems have not necessarily gone away. The other major factor limiting data quality is, as discussed, the high prevalence of percentage change estimates in the older data. Nonetheless, the method used for these gives good grounds to believe that the resulting series provide a reasonably consistent measure of the trend in military expenditure within each country, as has always been the primary goal of SIPRI military expenditure data. The standing warnings on the uncertainties involved in comparing data across countries, however, perhaps carry even greater force when considering countries where estimates have been used for a long period and/or involve a large adjustment to the older data. ${ }^{22}$

\section{Future improvements}

As a beta version, the extended SIPRI dataset is a work in progress, and we hope for further improvements before the planned public release in September 2016, and indeed beyond this. The data could be improved in many ways. First and foremost, we should like to find data sources for missing years. This may include sources that are available in printed form but not online, or which require direct, and in some cases personal, contact with national authorities to obtain. SIPRI has limited resources with which to pursue such sources, and it therefore 
greatly welcomes contributions from interested data users who may be able to access sources in their own countries.

Second, we would like to improve upon existing sources, for instance replacing secondary sources such as the IMF's GFSY with primary sources, or obtaining sources of data for omitted elements of military spending such as military pensions. (Some of the cases where very large percentage change adjustments have been made arise when military pensions are omitted from earlier sources, and they represent a very substantial proportion of the total for the years in which they are included.) Third, we would like to obtain new and updated studies for the USSR/Russia and China. This would require research by scholars with expert knowledge of these countries and, in the case of the USSR, probably access to declassified Soviet archives. This would therefore require funding. And fourth, we would like to obtain additional sources of economic data. The gap between the availability of current price local currency data and constant U.S. dollar data shown in Table 1 is due to gaps in consumer price inflation data. While we have found some additional national sources to supplement international online sources such as the IMF's and the World Bank's, it is likely that further searches of domestic sources could uncover more data. Again, SIPRI greatly welcomes contributions of data from anyone with access to such sources.

Beyond improvements to the military expenditure data itself, the SIPRI military expenditure project has two major outstanding priorities for further expanding the database. First is the provision of disaggregated military expenditure data, initially probably for a shorter (maybe 10-year) period, breaking down spending by function, e.g., personnel, operations and maintenance, procurement, $R \& D$, construction, and others, where this information is available. This is the subject of frequent requests for information to SIPRI, which at present we are unable to fulfill. As with the backdated military expenditure data itself, SIPRI has a large collection of source material, but producing such data would involve considerable conceptual work to take account of different national systems of classifying and reporting military expenditure. A large amount of time would also be required to go through these sources for all countries and construct consistent data series. Second, as a complement to the military expenditure data, SIPRI would like to compile data on civil security expenditure, to reflect a broader security concept and the increasingly blurred boundaries between military and civil security in many contexts. Both of these potential projects have been the subject of grant applications but - once again - as yet without success.

Various other extensions and deepening of the data can be envisaged. For example, we would like to see detailed studies of spending on paramilitary forces, ensuring comprehensive coverage, separating out spending on such forces (which not all countries would include in their military expenditure), and identifying more clearly the military role such forces fulfill. Similarly, a detailed survey of military pensions spending, providing comprehensive data, and identifying the different funding systems in use across countries would be important. To accomplish all, or any, of these potential projects will of course depend on resource availability.

\section{Conclusion}

SIPRI's military expenditure data collection effort was initiated 50 years ago. Commencing during the cold war-era, in an environment of a low level of trust between the two adversary blocs - the East and the West - it was one of the projects that contributed to the provision of a factual and balanced account of trends in the cold war arms race, and attempts to stop it, from an authoritative international source. Over time, new uses and approaches to analysis of military expenditure data have developed. SIPRI's military expenditure database has become an instrument of transparency, both between and within countries (especially in countries with a low degree of openness in security matters), and a source of data for academic research on the determinants and effects of resource allocation for military purposes. Over time, the demand for SIPRI's data has increased immensely and they have become the prime source of data globally in its field.

With the broader objectives and the increasing use of the SIPRI military expenditure data, the quality requirements of the data have increased. SIPRI has met these requirements to its best ability in spite of very limited resources. Fund raising for an ongoing project with the characteristics of a global public good (everyone wants to use, no one wants to fund) has been difficult.

Some of the key principles behind the credibility of SIPRI's military expenditure work have been:

- The importance of making clear methodological choices and to be entirely transparent about these (e.g., consistency over time is first priority);

- The use of open sources of data, carefully recorded so as to be able to provide detailed information to users - and to subsequent data collectors;

- Concentrating on doing a few things well rather than spreading efforts too broadly;

- Explaining and educating data users about the limitations associated with military expenditure data.

While these principles have been employed throughout most of 
the project's existence, there have been several mishaps and hiccups, as has been documented in this article. The history of the military expenditure database has thus been something of a game of "snakes and ladders," where years of progress have sometimes been undermined by major personnel transitions, failures of record keeping, and lack of adherence to sound methodological practices. Fortunately, and thanks largely to the extensive volunteer efforts of interns and guest researchers, these setbacks have now largely been rectified. As a result, the SIPRI database on military expenditure is able to continue to fulfill its role as a vital resource for researchers, policymakers, diplomats, civil society, media, and many others. At the same time, with additional resources, it would be possible to achieve a number of improvements and expansions of the data that would make additional major contributions to the research and analysis of questions related to the military sector.

Notes

1. Quotes: Nield (1969, p. 5).

2. Modest language quote: Blackaby (1969, p. 194, n. 1). Opportunity cost: Huisken (1973).

3. Blackaby (1969, p. 194, n. 1).

4. Israel: Rivlin (1983).

5. Ball (1983a; 1983b).

6. Tullberg and Hagmeyer-Gaverus (1987, p. 119).

7. SIPRI Military Expenditure Database. Sources and Methods. Last updated 5 April 2016. See https://www.sipri.org/ databases/milex/sources-and-methods\#definition-of-militaryexpenditure.

8. Sköns, et al. (1998, p. 240).

9. Cooper (1998, pp. 243-259); Wang (1999, pp. 334-349); Yentürk (2014). Numerous other experts have contributed data, estimates, and/or advice over the years, including Wael Abdul-Shafi (Iraq, Libya, Yemen), David Darchiasvili (Georgia), Dimitar Dimitrov (Bulgaria), Paul Dunne, Iñigo Guevara y Moyano (Mexico, Honduras), Gülay Günlük-Senesen (Turkey), Iduvina Hernández (Guatemala), Shir Hever (Israel), Nazir Kamal, Eugene Kogan (Georgia), Armen Koutoumdjian (Chile), Pavan Kumar (India), Guy Lamb (South Africa), Elina Noor (Indonesia), Tamara Pataraia (Georgia), Pere Ortega (Spain), Jamie Polanco (Colombia), Thomas Scheetz (Argentina, Guatemala, Paraguay), Ron Smith, Tasheen Zayouna (Iraq), and Ozren Zunec (Croatia).

10. Sköns, et al. (1998, p. 242).

\section{Kravis and Lipsey (1990).}

12. Comparison of selected countries: Sköns, et al. (1999, p. 332). Nonetheless: Sköns, et al. (2003, p. 305).

13. The other interns and guest researchers who worked on this, and without whom the project could not have been carried out, were Elena Deola, Lidwina Gundacker, Julius Heß, Giulia
Tamagni, and Mehmet Uye.

14. Swedish Riksbankens Jubileumsfond: "Expert workshop on SIPRI's new extended military expenditure data series." http://anslag.rj.se/en/fund/51062 [accessed 21 September 2016].

15. IMF Government Finance Statistics Yearbook: Various editions 1977-2014. http://www.imfbookstore.org/Search Result.asp?SEL=IMF.43\&Type=RLMc. United Nations Statistics Division: Classification of the Functions of Government. http://unstats.un.org/unsd/cr/registry/regcst.asp $? \mathrm{Cl}=4$ and $\mathrm{http}: / /$ unstats.un.org/unsd/cr/registry/regcs.asp? $\mathrm{Cl}=4 \& \mathrm{Lg}=1 \& \mathrm{Co}=02.1 .0$.

16. United Nations: http:/unstats.un.org/unsd/publications/ statistical-yearbook/ and http://www.unescap.org/resources/ statistical-yearbook-asia-and-pacific-2015. NATO: http://www.nato.int/cps/en/natohq/topics_49198.htm?.

17. Modest increase in reporting countries: The figure actually declines to 87 percent in 2015, but that is common with the most recent year of data as for some countries data is only available with a one-year's delay.

18. Principles applied: http://www.sipri.org/research/ armaments/milex/milex_database/copy_of_sources_methods. 19. Not all figures that are marked as SIPRI estimates are based on this percentage change approach. In some cases, estimates have been made of additional elements of spending outside the defense budget - such as arms imports - based on other information. In some cases, such as China, SIPRI's entire data series from 1989-2015 consists of estimates of a number of different extra-budgetary items, in addition to the official defense budget and other publicly-available elements of military spending.

20. Nine countries: They are Brazil, Colombia, Kuwait, Lebanon, Lesotho, Nigeria, the Philippines, Trinidad and Tobago, and Uruguay.

21. In fact, 1960 shows a significant drop in availability compared to 1959 as a large number of African countries became independent in 1960 , yet data for this year is only available for a few.

22. Problems not necessarily gone away: For example, a recent Nigerian government inquiry found that between 2007 and 2015 there had been around USD6 billion worth of "extra-budgetary interventions" for arms purchases. A significant portion of this was misappropriated by senior officials, however, and never led to any arms deliveries.

\section{References}

Ball, N. 1983a. Third-World Security Expenditure: A Statistical Compendium. Stockholm: Swedish National Defence Research Institute.

Ball, N. 1983b [2014]. Security and Economy in the Third World. Princeton, NJ: Princeton University Press.

Blackaby, F. 1969. "Section 1. Military Expenditure and the Trade in Arms." SIPRI Yearbook of World Armaments and 
Disarmament 1968/69. Stockholm: Almqvist \& Wiksell.

Cooper, J. 1998. "The Military Expenditure of the USSR and the Russian Federation, 1987-97." SIPRI Yearbook 1998. Oxford, UK: Oxford University Press.

Nield, R. 1969. "Preface." SIPRI Yearbook of World Armaments and Disarmament 1968/69. Stockholm: Almqvist \& Wiksell.

Huisken, R. 1973. "The Meaning and Measurement of Military Expenditure.” SIPRI Research Report. No. 10. Uppsala: Almqvist \& Wiksell. http://books.sipri.org/product_info? c_product_id=289 [accessed 21 September 2016].

Kravis, I.B. and R.E. Lipsey. 1990. "The International Comparison Program: Current Status and Problems." NBER Working Paper No. 3304. Cambridge, MA: National Bureau of Economic Research.

Rivlin, P. 1983. "The Burden of Defence: The Case of Israel." Appendix 7D. SIPRI Yearbook 1983. Oxford, UK: Oxford University Press. http://books.sipri.org/product_info? c_product_id=27 [accessed 21 September 2016].

Sköns, E. et al. 1998. "Sources and Methods for Military Expenditure Data.” Appendix 6C. SIPRI Yearbook 1998. Oxford, UK: Oxford University Press.

Sköns, E., et al. 1999. "Sources and Methods for Military Expenditure Data.” Appendix 7C. SIPRI Yearbook 1999. Oxford, UK: Oxford University Press.

Sköns, E. et al. 2003. "Military Expenditure.” SIPRI Yearbook 2003. Oxford, UK: Oxford University Press.

Tullberg, R. and G. Hagmeyer-Gaverus. 1987. "World Military Expenditure." SIPRI Yearbook 1987: World Armaments and Disarmament. Oxford, UK: Oxford University Press.

Wang, S. 1999. "The Military Expenditure of China, 1989-98." SIPRI Yearbook 1999. Oxford, UK: Oxford University Press.

Yentürk, N. 2014. "Measuring Turkish Military Expenditure." SIPRI Insights on Peace \& Security. No. 2014/1. http://books.sipri.org/product_info?c_product_id $=474$ [accessed 22 September 2016]. 